\title{
PERCEPÇÃO DE PESSOAS AMPUTADAS DE MEMBROS INFERIORES QUANTO AO USO DE TECNOLOGIA ASSISTIVA
}

\section{PERCEPTION OF LOWER LIMB AMPUTEES ON THE USE OF ASSISTIVE TECHNOLOGY}

\author{
Fabiola Hermes Chesani ${ }^{1}$ \\ Pyetra Prestes Negretti² \\ Carla Santos Grosskopf ${ }^{3}$
}

\begin{abstract}
Resumo: Os indivíduos amputados contam cada vez mais com uma diversidade de tecnologia assistiva para colaborar no processo de readaptação social. Deste modo, este trabalho tem como objetivo analisar a percepção de pessoas amputadas de membros inferiores quanto ao uso de tecnologia assistiva. Essa pesquisa é de caráter qualitativo, com uma amostra intencional de 10 participantes, sendo estas pessoas amputadas que utilizam tecnologia assistiva e que frequentam a Clínica de Fisioterapia e o Centro Especializado em Reabilitação II. Para a coleta de dados utilizou-se uma entrevista semiestruturado e analisadas com a Análise do Conteúdo Temática. Os resultados apontaram as categorias independência, extensão do corpo, orientações sobre utilização das tecnologias assistivas, lesões corporais, dificuldades de adaptação ao cotidiano e ergonomia do equipamento. O uso das tecnologias assistiva apresentou resultados satisfatórios em relação a autonomia e a participação social. A falta de orientações e de acompanhamento multiprofissional e um design inapropriado podem ser o causador lesões corporais e levar ao abandono da TA. Portanto, é imprescindivel um cuidado integral as pessoas amputadas.
\end{abstract}

Palavras-chave: Tecnologia assistiva; amputados; fisioterapia.

Abstract: Amputees increasingly rely on a variety of assistive technology to collaborate in the process of social readaptation. Therefore, this work aims at analyzing the perception of lower limb amputees regarding the use of assistive technology. This research is of a qualitative nature, with an intentional sample of 10 participants, these people being amputated using the assistive technology and attending the Physiotherapy Clinic and the Specialized Center in Rehabilitation II. For data collection, a semi-structured interview was employed and analyzed with the Analysis of Thematic Content. The results pointed to independence, body extension, guidance on the use of auxiliary technologies, body lesions, difficulty in adapting to daily life and equipment ergonomics. The use of TA showed satisfactory results in relation to autonomy and social participation. The lack of guidance and multiprofessional monitoring, as well as an inappropriate design, can be the cause of body injuries, and lead to the abandonment of TA. Therefore, it is essential to provide comprehensive care to amputees.

Keywords: Assistive technology; amputees; physiotherapy.

\section{INTRODUÇÂO}

Amputação é um procedimento cirúrgico caracterizado pela retirada total ou parcial de um ou mais membros do corpo. Estima-se que as amputações do membro inferior correspondam a $85 \%$ de todas as amputações de membros, apesar de não haver informações precisas sobre este assunto no Brasil (BRASIL, 2013). Durante 6 anos (2008-2013) ocorreram 1.183 casos de cirurgias de amputação dos membros

\footnotetext{
${ }^{1}$ Mestre em Saúde e Gestão do Trabalho. Docente do curso de Graduação em Fisioterapia na Universidade do Vale do Itajaí - UNIVALI. E-mail: fabiola.chesani@univali.br.

${ }^{2}$ Acadêmica de Fisioterapia. Universidade do Vale do Itajaí- UNIVALI. E-mail: pyetranegretti@hotmail.com.

${ }^{3}$ Acadêmica de Fisioterapia. Universidade do Vale do Itajaí- UNIVALI. E-mail: carla.saantos2011@hotmail.com.
} 
inferiores nos hospitais públicos no estado de Santa Catarina. As cirurgias de amputação de membros inferiores por diabetes mellitus, os homens com diabetes mellitus sofreram mais amputações quando comparados às mulheres diabéticas, $66,2 \%$ e 33,8\%respectivamente (SANTOS et al., 2018).

O número de vítimas de amputações tem crescido de forma preocupante, tendo como principais fatores de risco as doenças vasculares, o diabetes mellitus, o fumo, a hipertensão, o trauma e as malformações congênitas. As lesões podem deixar sequelas que podem interferir na perda da capacidade laborativa, com maior impacto socioeconômico no cuidado a esta pessoa e consequentemente, da qualidade de vida, associada à significativa morbidade, incapacidade e mortalidade (PEIXOTO et al., 2017).

As amputações podem acarretar várias alterações, não somente físicas, mas também emocionais e socioeconômicas. Estas alterações podem se tornar agravantes de complicações que geralmente ocorrem após a amputação, como deformidades em flexões em membros inferiores, excesso de partes moles, irregularidades ósseas, cicatrização inadequada, neuromas dolorosos, comprometimento vascular e complicações cutâneas, o que pode interferir no progresso das fases de recuperação funcional e consequentemente na qualidade de vida (LUZ et al., 2016).

O contexto da amputação, de modo geral, trata-se de um processo traumático para o indivíduo, buscando se estabilizar psicologicamente e socialmente diante de um momento crítico na vida do indivíduo. O sucesso da reabilitação é imprescindível para a independência do indivíduo para a realização de uma marcha equilibrada e das atividades cotidianas (PRIM; VIEIRA, 2016).

A Tecnologia Assistiva (TA) é utilizada para definir o conjunto de recursos e serviços que proporcionam ou ampliam habilidades funcionais, tendo como objetivo facilitar as atividades funcionais do indivíduo através da utilização de recursos empregados no auxílio nas diferentes atividades cotidianas, proporcionando melhora no desempenho funcional, igualdade de oportunidades e independência (CAVALCANTE et al., 2015). O uso da TA serve para o recrudescimento do poder, das desigualdades e da marginalização social, quanto para o reforço de práticas inclusivas, solidárias, diversificadas e de participação social, considerando a diferença enquanto expressão da vida e singularidade humana. Nessa perspectiva as tecnologias podem ampliar as possibilidades de autonomia e interação, potencializando a participação ativa como direito fundamental do ser humano (CONTE; OURIQUE; BASEGIO, 2017).

Os indivíduos amputados contam cada vez mais com uma diversidade de TA para colaborar no processo de readaptação social, dentre elas, podemos citar a prótese. Este dispositivo permite recuperar a independência funcional e a autonomia do paciente; o desempenho das atividades cotidianas desenvolvidas antes do trauma e contribuir para uma melhor participação social. As causas e as comorbidades associadas ao processo de amputação, bem como os aspectos demográficos (tipo de solo, terrenos, barreiras 
arquitetônicas, entre outros) influenciam diretamente neste processo de reabilitação e na adesão do indivíduo quanto ao uso deste dispositivo (ALMEIDA; SANTIAGO, 2017).

Os benefícios que a utilização das TAs proporcionam são vários, a necessidade do uso por pessoas amputadas se faz importante para a autonomia, todavia percebemos uma escassez de pesquisas que abordem quais os motivos que desencadeiam o uso e o não uso das TAs, por pessoas que sofreram algum tipo de amputação. Deste modo este trabalho tem como objetivo analisar a percepção de pessoas amputadas de membros inferiores quanto ao uso de TA.

\section{DESENVOLVIMENTO}

\subsection{Metodologia}

Trata-se de uma pesquisa de abordagem qualitativa, ou seja, de caráter exploratório, estimulando os entrevistados a pensarem livremente sobre algum tema, objeto ou conceito. Os sujeitos do estudo se constituíram por uma amostra intencional.

Participaram desta pesquisa sujeitos que possuíam algum tipo de amputação nos membros inferiores que utilizavam tecnologia assistiva e que frequentavam uma Clínica de Fisioterapia e um Centro Especializado de Reabilitação de uma cidade da região do Vale do Itajaí - SC. Os critérios de inclusão foram: ser amputado de membro inferior, usar a tecnologia assistiva a mais de 3 meses, receber atendimento em centros ou clínicas especializadas há mais de 6 meses, maiores de 18 anos e sem déficit de comunicação que impossibilitasse responder a entrevista.

Para a coleta de dados foram realizadas entrevistas semiestruturadas e individual a pessoas amputadas que usavam a tecnologia assistiva. Nesse tipo de entrevista utilizou-se um roteiro previamente elaborado, com perguntas abertas, possibilitando maior liberdade de resposta por parte dos entrevistados. A entrevista versou sobre os assuntos relacionados de como adquiriu a TA, tempo de uso, como foi a adaptação, barreiras no cotidiano, exclusão social e familiar.

As entrevistas foram realizadas na Clínica de Fisioterapia no período de março de 2018 a dezembro de 2018. A fim de não atrapalhar os atendimentos fisioterapêuticos, as entrevistas foram realizadas após a fisioterapia, numa sala reservada em que estavam presentes somente o entrevistador e o entrevistado. $O$ entrevistador foi previamente habilitado para aplicar as perguntas. As entrevistas foram gravadas num gravador de voz e posteriormente transcritas.

A coleta de dados só iniciou após a submissão e aprovação pelo Comitê de Ética e Pesquisa sob parecer $n^{\circ} 2.015 .431$ e seguiu os preceitos éticos da Resolução $n^{\circ}$ 466/12. Essa pesquisa recebeu apoio financeiro pelo Programa de Bolsas Universitárias de Santa Catarina-UNIEDU-Bolsa de Pesquisa do artigo 170, do estado de Santa 
Catarina. A pesquisa iniciou somente após o aceite e a assinatura do Termo de Consentimento Livre e Esclarecido dos participantes. Com o intuito de manter o anonimato os participantes receberam codinomes de $\mathrm{P}$ de participante seguido dos numerais 1,2 e 3 sucessivamente.

Após a coleta, os dados foram transcritos e analisados por meio da transcrição das gravações e posterior análise de conteúdo proposto por Bardin (2011), nessa análise, busca-se compreender as características, que estão por trás dos fragmentos de mensagens tornados em consideração, a utilização da análise de conteúdo prevê três fases fundamentais I: pré-análise, exploração do material e tratamento dos resultados - a inferência e a interpretação referencial. Na pré análise foi realizado a leitura flutuante das entrevistas transcritas. A descrição analítica os dados brutos das entrevistas foram transformados em categorias visando alcançar o objetivo da pesquisa de analisar a percepção de pessoas amputadas de membros inferiores quanto ao uso de TA.

\subsection{Resultados e discussão}

Participaram da pesquisa um total dez pessoas com amputação (tabela 1) deste total, duas mulheres (20\%) e oito homens (80\%). Em relação a idade dos entrevistados obteve-se uma média de 57,6 anos, onde o entrevistado mais novo apresentou a idade de 33 e o mais velho de 75 anos. Os participantes apresentam tipos de amputação diferenciados, sendo que três (30\%) apresentaram amputação transtibial a direita, três $(30 \%)$ apresentam amputação transtibial a esquerda, dois (20\%) apresentam amputação transfemoral a direita e dois (20\%) apresentam amputação transfemoral a esquerda.

Em relação aos motivos da amputação, seis (60\%) participantes vieram a realizar a amputação devido a complicações da doença Diabetes Melittus, dois (20\%) em virtude de acidente automobilístico, um (10\%) após complicações com artroplastia total de joelho e um (10\%) realizou a amputação devido ao avanço de osteossarcoma.

Tabela 1 - Perfil dos participantes da pesquisa

\begin{tabular}{c|c|c|c|c|c} 
Paciente & Sexo & Idade & Tipo de amputação & $\begin{array}{c}\text { Motivo da } \\
\text { amputação }\end{array}$ & TA que utiliza \\
\hline P1 & Masc. & 33 & $\begin{array}{c}\text { Amp. Transfemoral } \\
\text { (E) }\end{array}$ & $\begin{array}{c}\text { Acidente } \\
\text { automobilístico }\end{array}$ & Muleta axilar \\
\hline P2 & Masc. & 53 & $\begin{array}{c}\text { Amp. Transfemoral } \\
(\mathrm{D})\end{array}$ & $\begin{array}{c}\text { Acidente } \\
\text { automobilístico }\end{array}$ & $\begin{array}{c}\text { Prótese } \\
\text { endoesqueléti } \\
\text { ca }\end{array}$ \\
\hline P3 & Masc. & 75 & Amp. Transtibial (E) & Diabetes melittus & $\begin{array}{c}\text { Muleta } \\
\text { canadense e } \\
\text { Prótese } \\
\text { endoesqueléti } \\
\text { ca }\end{array}$
\end{tabular}




\begin{tabular}{c|c|c|c|c|c} 
P4 & Masc. & 35 & $\begin{array}{c}\text { Amp. Transtibial (E) } \\
\text { Diabetes melittus }\end{array}$ & $\begin{array}{c}\text { Muleta } \\
\text { canadense }\end{array}$ \\
\hline P5 & Fem. & 75 & $\begin{array}{c}\text { Amp. Transfemoral } \\
(\mathrm{D})\end{array}$ & $\begin{array}{c}\text { Complicação da } \\
\text { ATJ }\end{array}$ & $\begin{array}{c}\text { Cadeira de } \\
\text { rodas e } \\
\text { andador }\end{array}$ \\
\hline P6 & Masc. & 67 & Amp. Transtibial (D) & Diabetes melittus & $\begin{array}{c}\text { Muleta } \\
\text { canadense }\end{array}$ \\
\hline P7 & Fem. & 62 & Amp. Transtibial (D) & Diabetes melittus & $\begin{array}{c}\text { Cadeira de } \\
\text { rodas e } \\
\text { andador }\end{array}$ \\
\hline P8 & Masc. & 64 & $\begin{array}{c}\text { Amp. Transfemoral } \\
(\text { E) }\end{array}$ & Diabetes melittus & $\begin{array}{c}\text { Andador e } \\
\text { cadeira de } \\
\text { rodas }\end{array}$ \\
\hline P10 & Masc. & 60 & $\begin{array}{c}\text { Amp. Transtibial (E) } \\
\text { e amp. Das falanges } \\
\text { (D) }\end{array}$ & CA de ossos & $\begin{array}{c}\text { Muleta } \\
\text { canadense }\end{array}$ \\
\hline & Masc. & 52 & $\begin{array}{c}\text { Amp. Transtibial (D) } \\
\text { rodas }\end{array}$ \\
\hline
\end{tabular}

Fonte: Os autores.

Os participantes utilizam mais de uma TA no seu dia em virtude de vários fatores, a muleta canadense foi utilizada por quatro entrevistados, quatro usavam cadeira de rodas, três utilizavam andador, dois usavam prótese endoesquelética, e um fazia uso da muleta axilar. Após várias leituras aprofundadas das transcrições emergiram as seguintes categorias: independência, extensão do corpo, orientações sobre utilização das tecnologias assistivas, lesões corporais, dificuldades de adaptação ao cotidiano e ergonomia do equipamento.

\subsubsection{Independência}

O uso da TA segundo os entrevistados, possibilita possibilidade de locomoção e realização de diversas atividades como trabalhar, fazer trabalhos domésticos, interagir socialmente, assim se tornando mais independentes, como pode ser observado nas falas:

\footnotetext{
"Me senti livre, porque podia andar novamente, foi a mesma sensação quando andei de bicicleta pela primeira vez...Sempre uso elas para fazer tudo nem sei informar quanto tempo uso ela, porque é muito" P1

"Eu depois que operei a perna, já fui mais independente! Sempre fui de me virar sabe, tipo a adaptação que tem no meu carro, não mandei fazer, eu mesmo que arrumei. Fui lá, já adaptei, já comecei a andar, é ruim ficar dependendo dos outros, a gente precisava mudar e tudo dependendo de alguém pra levar, pra fazer. Eu mesmo que fiz, eu trabalho com oficina, tem solda e essas coisas, eu mesmo que fiz." P4

"A cadeira de rodas eu uso praticamente o dia todo para fazer o trabalho de casa. Eu lavo, passo, cozinho e cuido de toda a casa. " P7

"Como disse agora consigo dirigir, quando precisa subir para arrumar alguma coisa lá em casa eu faço, até para lavar meu caminhão eu faço." P2
} 
"Ela me serve muito então graças a Deus com ela eu consigo me virar, ver as pessoas, sair de casa." P10

Campos et al. (2018) afirmam que a partir do momento em que a pessoa sofreu amputação e durante o processo de reabilitação, sua vida produtiva é prejudicada, pois ela se ausenta do trabalho durante esse processo de recuperação. Diante desse contexto, a reintegração às atividades laborais depende dos aspectos da reabilitação do indivíduo, mas também do próprio mercado de trabalho, tornando-se necessário para esses indivíduos um programa de reabilitação com equipe multiprofissional para um bom prognóstico terapêutico.

Após a amputação de membros inferiores, a restauração da mobilidade e da função locomotora é um dos objetivos primários do paciente e dos programas de reabilitação, pois é considerada um dos componentes básicos da independência funcional, porém, diferentes fatores podem gerar alterações no padrão de normalidade. Alguns dos fatores que limitam a realização de marcha pelos amputados são os altos custos das próteses, a escassez de recursos humanos capacitados e a dificuldade na interpretação de seus resultados (BALARDINA, et al., 2018).

Segundo Silva, Vey e Vendrusculo (2016), um fator que pode estar relacionado aos aspectos emocionais é o uso ou não da prótese. Percebe-se que a essa TA facilita o indivíduo a voltar a trabalhar, correr, praticar esportes, deambular dentro de casa ou ir até a esquina realizar compras básicas, adquirindo, desta forma, maior independência. O paciente amputado, que faz uso da prótese, possui maior liberdade e segurança para realizar atividades de vida diária e participar de eventos sociais.

O sentido atribuído ao trabalho para as pessoas com deficiência não se reduz apenas à questão de sobrevivência, mas o sentido é também percebido como um dos principais meios de inserção social que possibilitam a essas pessoas a oportunidade de demonstrar suas capacidades/ habilidades e contribuir com a sociedade por meio do seu trabalho, que confirma a relação entre a relevância do trabalho e a integração social na organização da autonomia dessa pessoa (CARVALHO-FREITA, et al., 2018).

A independência se baseia muito na relação com o adequado uso da TA, o que promove a autonomia no realizar as tarefas de atividades de vida diária, lazer e trabalho. De forma que a TA ajuda o indivíduo a alcançar metas e atividades desejadas, se adaptar com seu estilo de vida, rotinas e preferências.

\subsubsection{Extensão do corpo}

As pessoas amputadas quando se adaptam bem a sua TA, conseguem utilizá-la de forma mais funcional possível, chegando a ver o dispositivo assistido como uma extensão do seu corpo. Podemos observar esse contexto nas seguintes unidades de registro: 


\begin{abstract}
"Essa aqui (prótese) to usando direto uns 2 meses.As vezes uso o dia todo, vezes durmo, depois do meio dia não a noite." P3

"Uso o tempo todo, pra ir em todo lugar, até para dormir rapidinho depois do almoço eu uso ela (prótese). Ah por preguiça de colocar de novo, não é difícil só preguiça mesmo." P2

"Com essa que tenho hoje (muleta) sim ela é mais leve consigo passar mais rápido acho que consigo pular até corda com ela." P6

"Eu aprendo rápido e dou até dicas para quem está passando necessidades por aí, de como arrumar a altura, trocar borracha e a espuma as vezes até pra trocar de muleta eu ajudo." P1
\end{abstract}

Após uma amputação independentemente da sua causa, a pessoa amputada inevitavelmente apresenta um membro fantasma, ou seja, a ilusão de que o membro amputado ainda existe, com a percepção de que altera sua posição ou que manifesta dor. A presença de dor persistente, seja no coto de amputação, dor fantasma ou no membro contralateral, pode interferir negativamente na obtenção de marcha no paciente amputado, pois o mesmo pode transmitir essa dor para a prótese impedindo sua funcionalidade (SOUZA FILHO, et al., 2016).

O programa de reabilitação para essa situação visa recuperar a autonomia para locomoção, se possível com prótese, e para as atividades da vida diária, sem deixar de cuidar dos aspectos cognitivos, emocionais e sociais. A adesão à reabilitação atua como elemento motivador no enfrentamento à amputação e ao quadro de dor fantasma e possibilita ao paciente compartilhar os problemas desta fase e reforçar o uso correto e frequente da prótese indicada, medidas que diminuem a intensidade dolorosa (CHAMLIAN, et al., 2016).

Uma das grandes expectativas de uma pessoa amputada é sobre a utilização da prótese, e assim conseguir realizar marcha e ganhar autonomia, entretanto uma grande barreira é a dor fantasma que impede a progressão na reabilitação e o uso adequado do dispositivo assistido, e nesse momento a equipe multiprofissional deve intervir dando suporte físico e emocional para que o mesmo alcance funcionalidade com a prótese.

\title{
2.2.3 Orientações sobre utilização das tecnologias assistivas
}

O processo de reabilitação da pessoa amputada necessita de um trabalho multidisciplinar, além de recursos que auxiliem na deambulação do indivíduo em casos de amputação dos membros inferiores, contudo as orientações e supervisão da utilização desta tecnologia assistiva irão influenciar no uso adequado e sucesso da reabilitação, como identificamos nas seguintes falas:

"Lá onde foi feito a prótese, só pediram para dar umas três caminhadas e olharam e pronto já podia usar e não falaram mais nada e fui para casa." P9 


\begin{abstract}
"Não, nada nada, eu comecei a andar com o andador e percebi que eles estavam altos, aí eu fui em uma consulta em Florianópolis e lá tinha uma fisioterapeuta e ela arrumou ele direitinho." P7

"Treinamento foi aqui na fisioterapia, agora eu faço de tudo, subo em árvore, viajo com meu caminhão, e olha que faço viagem para bem longe lá na serra e tudo com a minha prótese, só que eu agora venho para cá porque quero aprender a andar melhor com ela." P8
\end{abstract}

Há um número crescente de indivíduos que adquirem dispositivos de TA diretamente com algum vendedor comercial, sem passar pelo processo de avaliação, prescrição, treino e acompanhamento por profissionais apropriados, como médicos, fisioterapeutas e terapeutas ocupacionais. Isso pode direcionar a uma alta incidência de pessoas que adquirem dispositivos inapropriados, com descompasso em relação às necessidades funcionais do sujeito, às limitações na mobilidade, preferências pessoais, ao ambiente e outras combinações importantes em relação ao uso de dispositivos, o que diminui tanto a funcionalidade, quanto a satisfação em relação ao produto (PAULISSO, 2016).

O profissional deve favorecer a participação ativa do usuário na prescrição e na seleção e deve ter atenção a possíveis dores, desconfortos, insatisfações, entre outros fatores negativos associados ao uso. Também deve oferecer acompanhamento, para treino e orientações específicas; para reavaliações e reajustes e para envolver fabricante e usuário durante todo o processo. Para facilitar a sequência de prescrição e acompanhamento do uso, ferramentas como avaliações padronizadas devem ser utilizadas, pois podem favorecer a compreensão dos sujeitos, permitir que os profissionais percebam áreas importantes a serem consideradas e para conferir se há melhora na satisfação e na funcionalidade após determinado período de tempo de uso do dispositivo (COSTA et al, 2015).

As próteses atuais contribuem para o aperfeiçoamento da marcha do amputado, mas apesar do avanço das tecnologias, existe ainda um grande número de pacientes reabilitados que voltam para as clínicas de reabilitação por algum déficit na marcha e/ou equilíbrio, e por desajustes nos dispositivos protéticos que acabam por proporcionar uma adaptação não eficiente do paciente (PINHEIRO; GUTERRES, 2017).

A fisioterapia pode intervir na prevenção e tratamento destas complicações por meio de diferentes tipos de intervenção, como treinamento para melhorar a força da extremidade amputada, cinesioterapia e principalmente orientação para a colocação da prótese e uso da mesma para alcançar os objetivos de obter uma deambulação ativa, independente e o mais fisiológico possível (com o uso da prótese) contribuindo para a reinserção do indivíduo na sociedade (LUZ, et al., 2016).

Para que o uso da prótese seja possível para os pacientes amputados, é necessário que o tratamento de reabilitação apresente um período de tempo maior, com foco na fisioterapia pré e pós-protética, para que as fisioterapias sejam continuadas até 
que se alcance uma adaptação efetiva do uso do dispositivo, de forma que a interação entre o usuário e o produto torne-se ideal.

\subsubsection{Lesões corporais}

A falta de investimento em design prático e confortável nas tecnologias assistivas resultou em próteses pesadas, cadeiras de rodas ineficientes e difíceis de manobrar, exemplo, onde os usuários são expostos a acidentes e lesões corporais devido ao uso, como os participantes relatam abaixo:

\footnotetext{
"Cai três vezes, mas foi de cadeira de rodas. Em casa. Com alguém me empurrando, bateu em um obstáculo e a cadeira para frente. Duas vezes ainda eu estava com minha neta no colo." P2

"O médico que me amputou falou para não andar de muletas, porque eu cair e quebrar o fêmur ou o quadril é um grande risco para os amputados." P10
}

"Não a canadense eu tenho lá, mas é horrível, aquilo força o ombro acaba com os pulsos sinto muita dor." P5

Conforme Cavalcanti, et al. (2018) mencionam, a cadeira de rodas é um dispositivo de tecnologia assistiva com funções diversas que visa fornecer adequação postural, possibilitar mobilidade funcional e assistir no transporte de pessoas com deficiência física. Quando adequadamente prescrita às necessidades da pessoa, independentemente da idade, promove conforto, simetria e estabilidade na postura sentada, assim como favorece a autonomia e a independência do usuário na realização de suas atividades do dia a dia.

Em um estudo realizado por Ossada et al (2014) com 10 entrevistados no Hospital Universitário da Universidade Estadual de Londrina, os participantes revelaram que os braços das cadeiras de rodas (CR) devem ser ajustados para que permitam segurança sem interferir nas transferências, e removíveis para ajudar os cuidadores no transporte da mesma. Os braços ajustáveis e removíveis proporcionam segurança, uma vez que além de ser removível ajustado, não ultrapasse as dimensões da $\mathrm{CR}$, pois isso pode levar ao abandono da cadeira de rodas, o que deixaria o paciente vulnerável e sem segurança às quedas. A CR deve ser segura, confortável, leve para otimizar seu uso e possibilitar a independência na locomoção e nas estratégias de movimento.

De acordo com Medeiros, Coelho e Guerra (2018) o indivíduo pode desenvolver a síndrome pós queda, que pode ser explicada através do medo descontrolado de não se locomover, mesmo que o mesmo não apresente qualquer tipo de patologia ou problema na deambulação, podendo também desencadear lesões ósseas e musculares e influenciar até nas relações sociais. Visto que um paciente em processo de reabilitação que perde a confiança em se mover, pode retroceder toda sua evolução.

Segundo Grillo et al (2018) existem quatro tipos de muletas: axilar, de tríceps, 
de plataforma e de antebraço (modelo canadense). Dentre esses tipos, destacam-se as de modelo canadense e axilar, em termos de oferta no mercado e de preferência pelos usuários. Por serem modelos que transferem parte do peso do corpo para os membros superiores, o uso prolongado acaba gerando lesões e desconfortos, dentre elas podem ser citadas: degeneração da articulação do ombro, lesões nos braços, mãos e áreas peitorais, síndrome do túnel do carpo e inclusive a possibilidade de neuropatias braquiais compressivas.

Mesmo existindo vários modelos de TA é indispensável que ocorra uma avaliação, adaptação e consequente prescrição correta para cada indivíduo, levando em consideração a singularidade de cada sujeito. Caso não ocorra esta adequação podem levar a lesões musculoesqueléticas e até mesmo quedas.

\subsubsection{Dificuldades de adaptação ao cotidiano}

Passar pelo processo de adaptação não é uma tarefa fácil, desde o processo cirúrgico que envolve a perda de um membro, pois remete ao terror, mutilação e incapacidade. Porém, ela deve ser considerada como o início de uma nova fase, cujo principal objetivo é manter e/ou devolver a funcionalidade e independência do paciente. Quando os recursos tecnológicos que auxiliam nessa fase não são funcionais ou práticos, podem influenciar o processo de reabilitação inclusive, pelo difícil manuseio como podemos identificar nas falas a seguir:

\footnotetext{
"O cara acostumado a fazer sozinho. Só o fato de querer fazer uma coisa e uma mão fica segurando e não conseguir fazer totalmente sozinho. Usa essa e consegue libera a outra. P1"

"Para pegar as coisas eu tenho que soltar elas e me apoiar na parede na cadeira aonde der." P7

"É que as vezes o andador não pode bater em nada, ele dá uma travadinha." P2

"Com as muletas esbarro sempre nas pessoas, e quando uma cai sempre quebra alguma coisa e horrível para pegar do chão." P5
}

Os usuários permanentes investem mais nas muletas, porém não encontram muitas opções no mercado que se adequem às suas necessidades específicas. A maior clientela fica por parte dos usuários temporários, que não estão dispostos a dispor de um grande investimento, buscando muitas vezes empréstimos ou os serviços de aluguéis. Quanto à experiência vivida pelo usuário e o padrão de uso, existe uma tendência à descontinuação do uso da muleta. O abandono do uso se dá tanto pelas lesões causadas, quanto pela dificuldade encontrada na realização de atividades cotidianas (GRILLO et al, 2018).

Boiani et al (2015) referem que apesar das muletas axilares terem baixo custo de 
aquisição, as muletas canadenses têm como possibilidade a realização de atividades da vida diária, sem que as muletas se soltem. E o andador, no entanto, apresenta desvantagens quanto à existência de obstáculos como tapetes e pisos irregulares, tornando-os de difícil uso ou perigoso.

O estudo de Boiani (2018) com a participação de 40 indivíduos, na avaliação da satisfação dos usuários de andador, verificou que a facilidade do uso e estabilidade estavam relacionados aos aspectos de maior satisfação. A facilidade com o ajuste e peso do andador foram os aspectos relacionados com menor satisfação do usuário. Quanto aos aspectos vistos como mais importantes em relação a satisfação com o dispositivo, a segurança, facilidade de uso e conforto foram os mais frequentemente apontados, sugerindo uma preocupação com o risco de queda e questões práticas de uso.

Glisoi et al (2012) observaram que a maioria das pessoas que utilizam TA não foi instruída sobre o uso correto e muitas vezes utiliza modelos inadequados, danificados ou com altura inapropriada. Por isso, os profissionais de saúde devem rotineiramente avaliar a TA de seus pacientes para garantir boa altura, ajuste e manutenção, e também orientar quanto ao uso correto do dispositivo. Quando há indicação para o uso, este deverá ser prescrito após a avaliação de variáveis como: força muscular atual do indivíduo, resistência, equilíbrio, marcha, função cognitiva, dor e demandas ambientais.

Quando a combinação entre o dispositivo e a pessoa está ruim, indicam riscos de abandono, uso parcial, relutância ou não uso da TA. Nesses casos, o equipamento deve ser melhor ajustado às necessidades da pessoa, ser indicado outro dispositivo e/ou a pessoa deverá receber melhor treinamento ou condições para a aquisição deste (ALVES, 2017).

\subsubsection{Ergonomia do equipamento}

Tecnologias assistivas que possuem um design prático e fácil de manusear colaboram para seu bom desempenho, consequentemente influenciando se este será utilizado no dia a dia. Um recurso de estrutura que não é prático o suficiente, somado com a utilização incorreta devido a falta de orientação para o manuseio, podem levar a possíveis lesões e até mesmo o abandono, como nas próximas falas podemos observar:

\footnotetext{
"Agora ela ajuda bastante, mas antes para cá, estava me prejudicando. Não estava pisando, estava trancando, estava pulando muito." P4

"Eu já andava sozinha sem cadeira só com a prótese, mas infelizmente ela começou a machucar e dar coágulo de sangue e devido eu ser diabética, fiquei com medo e abandonei ela, com medo de ter que amputar de novo minha perna." P7

"Eu comprei uma prótese, mais ai não deu não combinou porque atingiu meu osso e cortou minha pele e daí minha perna tomou de
} 
câncer e não pude mais usar. Aí tive que cortar a perna eu tinha joelho e tudo, mas cortei para não espalhar o câncer e perder a perna toda." P9

Em estudo recente realizado por Costa et al (2015), com o objetivo de identificar fatores relacionados ao abandono de dispositivos de TA foi identificado, em revisão da literatura entre os anos de 2002 e 2013, que as variáveis que levam ao abandono, são: o estado físico do usuário, falta de informação, falta de treinamento de profissionais e dos usuários, dor, limitações funcionais, preferência por outro dispositivo ou pela utilização de capacidades remanescentes, peso elevado do dispositivo, alterações nas condições da tecnologia, dificuldade de uso, insatisfação, desconforto, inadequação/inapropriada e barulho. Neste estudo também foi constatado que muletas, andadores e cadeira de rodas são os principais dispositivos em mobilidade abandonados e que a cadeira de rodas lidera os índices, considerando também dispositivos de outras áreas de aplicações da TA, como recursos de comunicação alternativa (COSTA et al, 2015).

Os profissionais da área da saúde apontam que as muletas axilares e canadenses são os produtos assistivos que mais atendem a sociedade. Os usuários temporários são uma grande parcela, bem como pacientes neurológicos e amputados. Eles atentam para o grande número de lesões causadas pela falta de ergonomia e conforto, sendo recorrente o tratamento dessas, o que torna a vivência com as muletas ainda mais difícil (GRILLO et al, 2018).

Conforme Pinheiro e Guterres (2017) as exigências de gastos de energia metabólica para andar com uma prótese são maiores do que durante a marcha normal e, portanto, requerem preparação e formação. Contudo, destaca-se relevância de desenvolverem próteses que minimizem o gasto energético e aumentem a eficiência mecânica do amputado, pois esses dispositivos apresentam um peso bastante elevado, e quanto mais pesada é a prótese, maior é o gasto energético exigido e mais lento é o caminhar, a mobilidade e consequentemente a produtividade do indivíduo.

\section{CONCLUSÃO}

As pessoas que possuem alguma amputação nos membros inferiores apresentam dificuldades de locomoção e assim perdem sua autonomia. Entretanto com o uso das TAs esse contexto muda, pois após a escolha, adequação e treinamento do equipamento os usuários demostram resultados satisfatórios em relação a funcionalidade e apresentam melhora de autonomia, participação social e a volta ao mercado de trabalho. É de suma importância para uma boa aceitação da TA uma equipe multiprofissional que oriente o usuário a adquirir um dispositivo de qualidade que se encaixe nas suas expectativas físicas e funcionais proporcionando independência.

Contudo, ainda observam-se lesões corporais devido ao mau uso, assim como o design de TA utilizada pode não ser prático, interferindo no processo de adaptação ao 
dia a dia. Ambas situações corroboram ao abandono da TA que poderiam ser evitadas com orientações de profissionais específicos sobre o uso e treinamento adequado, prescrição do recurso apropriado e assim obter-se sucesso na reabilitação e voltar as atividades de vida diária e laborais da forma mais funcional e confortável possível.

\section{REFERÊNCIAS}

ALMEIDA, A. O.; SANTIAGO, A. K. C. Tradução e adaptação cultural das escalas Amputee Mobility Predictor (AMP) e Houghton Scale of Prosthetic use - escalas preditoras da mobilidade em amputados de membros inferiores. 2017. Monografia (Graduação em Fisioterapia) - Universidade Federal de Sergipe, Lagarto, 2017.

ALVES, A. C. J. Avaliação de tecnologia assistiva predisposição ao uso: ATD PA Br: versão brasileira. Brasília: Editora Universidade de Brasília, 2017. 34 p.

BALARDINA, A. L. et al. Análise Cinemática Linear e Angular da Marcha em Pacientes Amputados Transfemorais Protetizados. Journal of Health Sciences, v. 20, n. 2, p. 125-130, 2018.

BARDIN, L. Análise de Conteúdo. 70. ed. Lisboa: LDA, 2011.

BOIANI, J. A. M. Design e tecnologia assistiva: avaliação da mobilidade, satisfação e semântica de andador para idosos. 2018. 70f. Dissertação (Mestrado) - Faculdade de Arquitetura Artes e Comunicação, Universidade Estadual Paulista, Bauru, 2018.

BOIANI, J. A. M. et al. Prescrição e uso de andadores para idosos: uma demanda para o design ergonômico. Blucher Design Proceedings, São Paulo, v. 2, n. 1, p. 585-597, 2015.

BRASIL. Diretrizes de atenção à pessoa amputada. Brasília: Ministério da Saúde, 2013.

CAMPOS, P. V. C. et al. Barreiras e facilitadores para o retorno ao trabalho vivenciado por pessoas amputadas de membros inferiores, sob a ótica das diretrizes brasileiras.

Cadernos Brasileiros de Terapia Ocupacional, v. 26, n. 1, 2018.

CARVALHO-FREITAS, M. N. et al. Retorno às atividades laborais entre amputados: Qualidade de vida no trabalho, depressão e ansiedade. Revista Psicologia:

Organizações e Trabalho, v. 4, n. 1, p. 468-475, 2018.

CAVALCANTE, L. D. W. et al. Assistive technology for visually impaired women for use of the female condom: a validation study. Revista escola de enfermagem da USP, São Paulo, v. 49, n. 1, p. 14-21, 2015.

CAVALCANTI, A. et al. Percepção dos responsáveis de crianças e adolescentes. Rev Ter Ocup Univ., São Paulo. v. 1. n. 29. p. 27-33. 2018.

CHAMLIAN, T. R. et al. Dor relacionada à amputação e funcionalidade em indivíduos com amputações de membros inferiores. Acta Fisiatr, v. 21, n. 3, p. 113-116, 2016.

CONTE, E.; OURIQUE, M. L. H.; BASEGIO, A.C. Tecnologia Assistiva, direitos humanos e educação inclusiva: uma nova sensibilidade. Educação em Revista, v. 33, n. 2, p. 28, 2017. 
COSTA, C.R. da et al. Dispositivos de tecnologia assistiva: fatores relacionados ao abandono. Cadernos de Terapia Ocupacional da UFSCar, v. 23, n. 3, 2015.

LUZ, J. P. et al. Fisioterapia em pacientes com amputação transtibial: revisão sistemática. ConScientiae Saúde, v. 15, n. 1, p. 1-6, 2016.

GLISOI et al. Dispositivos auxiliares de marcha: orientação quanto ao uso, adequação e prevenção de quedas em idosos. Sociedade brasileira de geriatria e gerontologia, v. 6, n. 3, p. 261-272, 2012.

GRILLO, A. T. P. et al. Muleta modular: da identificação das oportunidades ao protótipo. Braz. Ap. Sci. Rev., v. 2, n. 6, p. 1885-1900, 2018.

MEDEIROS, C. M. R.; COELHO, C. S. C.; GUERRA, M. O. Treinamento muscular na prevenção de lesões musculo-esqueleticas em idosos. Health Research Journal. v. 1, n. 1, p. 92-107, 2018.

OSSADA, V. A. Y. et al. A cadeira de rodas e seus componentes essenciais para a locomoção de pessoas com tetraplegia por lesão da medula espinhal. Acta Fisiatr. v. 4, n. 21, p. 162-166, 2014.

PAULISSO, D. C. Adaptação transcultural do instrumento Functional Mobility Assessment (FMA), para uso no Brasil. 2016. 118 f. Dissertação (Mestrado) Universidade Federal de São Carlos, São Carlos, 2016.

PEIXOTO, A. et al. Prevalência de amputações de membros superiores e inferiores no estado de Alagoas atendidos pelo SUS entre 2008 e 2015. Fisioterapia e Pesquisa, v. 24, n. 4 , p. 378-384, 2017.

PINHEIRO, L. R.; GUTERRES, L. M. B. Análise da satisfação de amputados usuários de próteses de membros inferiores. Revista da Mostra de Trabalhos de Conclusão de Curso., v. 1, n.1, p. 127-144, 2017.

PRIM, G. de S.; VIEIRA, M. L. H. O design e novas tecnologias para o avanço das próteses: exploração, inovação e avaliação. Blucher Design Proceedings, v. 9, n. 2, p. 4450-4457, 2016.

SANTOS, K. P. B. dos et al. Carga da doença para as amputações de membros inferiores atribuíveis ao diabetes mellitus no Estado de Santa Catarina, Brasil, 20082013. Cadernos de Saúde Pública, v. 34, n. 1, 2018.

SILVA, S. C. da; VEY, A. P. Z.; VENDRUSCULO, A. P. Hidrocinesioterapia na qualidade de vida de amputados de membros inferiores unilaterais. Disciplinarum Sciential Saúde, v. 15, n. 1, p. 65-74, 2016.

SOUZA FILHO, L. F. M. et al. Tratamento da dor Fantasma em Pacientes Submetidos à Amputação: Revisão de Abordagens Clínicas e de Reabilitação. Revista Brasileira de Ciências da Saúde, v. 20, n. 3, p. 241-246, 2016. 